\begin{tabular}{|c|l|}
\hline Title & Production of ketones from pyroligneous acid of woody biomass pyrolysis over an iron-oxide catalyst \\
\hline Author(s) & Mansur, Dieni; Y oshikawa, Takuya; Norinaga, Koyo; Hay ashi, Jun-ichiro; Tago, Teruoki; Masuda, Takao \\
\hline Citation & $\begin{array}{l}\text { Fuel, 103,130-134.1016/.fuel.2011.04.003 } \\
\text { https://doi.org/10.101/201 }\end{array}$ \\
\hline Issue Date & 201301 \\
\hline Doc URL & http://hdl.handle.net/2115/51059 \\
\hline Type & article(author version) \\
\hline File Information & Fue103_130-134.pdf \\
\hline
\end{tabular}

Instructions for use 


\title{
Production of ketones from pyroligneous acid of woody biomass pyrolysis over an iron-oxide catalyst
}

\author{
Dieni Mansur $^{\mathrm{a}, \mathrm{c}}$, Takuya Yoshikawa ${ }^{\mathrm{a}}$, Koyo Norinaga $^{\mathrm{b}}$, Jun-ichiro Hayashi $^{\mathrm{b}}$, Teruoki Tago $^{\mathrm{a}, *}$, Takao Masuda $^{\mathrm{a}}$ \\ ${ }^{a}$ Division of Chemical Process Engineering, Faculty of Engineering, Hokkaido University, N-13 W-8 Kita-Ku, Sapporo 060-8628, Japan \\ ${ }^{b}$ Institute for Materials Chemistry and Engineering, Kyushu University, 6-1 Kasuga-koen, Kasuga 816-8580, Japan \\ ${ }^{c}$ Research Center for Chemistry, Indonesian Institute of Sciences, Kawasan Puspiptek Serpong, Tangerang, Banten 15314, Indonesia \\ *Corresponding author. Tel.: +81 11706 6551; fax: +81 117066552 \\ E-mail address: tago@eng.hokudai.ac.jp (T. Tago).
}

\begin{abstract}
Catalytic upgrading of pyroligneous acid, by-product from slow pyrolysis of woody biomass for char production, was carried out using zirconia-supported iron-oxide catalysts under a steam atmosphere at temperatures ranging from 623 to $723 \mathrm{~K}$, and the effect of $\mathrm{ZrO}_{2}$ content in the $\mathrm{ZrO}_{2}-\mathrm{FeO}_{\mathrm{X}}$ catalysts on catalytic activity and ketone yields was investigated. It was demonstrated that hydroxyacetone and carboxylic acids (acetic and propionic acids) in the pyroligneous acid were converted into aliphatic ketones (acetone and 2-butanone) via a ketonization reaction over the $\mathrm{ZrO}_{2}-\mathrm{FeO}_{\mathrm{X}}$ catalyst. However, reaction inhibition by metal impurities in the pyroligneous acid such as potassium (K) and magnesium (Mg) was also observed. These metal impurities could be removed from the pyroligneous acid without changing the organic composition by using an ion-exchange resin. The removal of the metal impurities was effective in increasing the ketone yields. Moreover, as the $W / F$ value ( $W$ : amount of catalyst, and $F$ : flow rate of the pyroligneous acid in the feed) increased, the ketone yield increased up to approximately $30 \mathrm{C} \mathrm{mol \%}$, and the ketone fraction in the liquid product reached $55 \mathrm{C} \mathrm{mol \% .}$
\end{abstract}

Keywords: Ketones; Pyroligneous acid; Woody biomass; Iron-oxide catalyst 


\section{Introduction}

In response to the need for alternatives to petroleum-based energy and the desire to use renewable resources for chemical production, many efforts have recently been concentrated on conversion of biomass into energy and useful chemicals. Sustainability in energy recovery from biomass such as steam gasification of char is becoming attractive because biomass to energy conversion adds no additional greenhouse gases to the atmosphere $[1,2]$. The char as highquality solid fuel is produced from pyrolysis and its higher yield can be recovered by slow pyrolysis than fast or flash ones $[3,4]$. During slow pyrolysis (low-moderate temperature and slow heating rate process), volatile matters are condensed into two liquid fractions, an aqueous and an organic liquid fractions. The organic liquid fraction has higher carbon concentration and heating value than the aqueous one because the aqueous fraction is characterized by high water content, relative low carbon concentration, and very low heating value [5]. Therefore, the organic liquid fraction has potentiality for fuel application [6]. The aqueous fraction, also known as pyroligneous acid, will create waste-water disposal problems, although this could be incinerated $[3,5]$.

The pyroligneous acid, a by-product from slow pyrolysis of woody biomass for char production, dissolves organics (such as acetic acid, methanol, phenolic compounds) in water. Therefore, the possible wet utilization basis and catalytic upgrading is required for its conversion to higher value chemicals. In the previous study, we have developed $\mathrm{ZrO}_{2}-\mathrm{FeO}_{\mathrm{X}}$ catalysts to selectively produce valuable chemicals such as phenol and ketones from palm waste, sewage sludge, and coliform-fermented residue-derived tars [7-9]. Because the $\mathrm{ZrO}_{2}-\mathrm{FeO}_{\mathrm{X}}$ catalyst possesses oxidation activity towards hydrocarbons, it is possible to reduce the amount of deposited carbonaceous residue on the catalyst [10].

In aqueous solution of pyroligneous acid, many organics such as carboxylic acid and alcohol were contained. Because the $\mathrm{ZrO}_{2}-\mathrm{FeO}_{\mathrm{X}}$ catalysts possess ketonization activities from carboxylic acid and alcohol, we examined the catalytic upgrading of the pyroligneous acid derived from woody biomass over $\mathrm{ZrO}_{2}-\mathrm{FeO}_{\mathrm{X}}$ catalysts to produce useful chemicals. Here, the catalytic upgrading is the process integration of slow pyrolysis for biomass utilization. The effects of the reaction temperature, catalyst composition, metal impurities in the pyroligneous acid, and $W / F$ values on the catalytic activity and product yields were investigated. Moreover, catalytic reactions using model compounds were also carried out in order to clarify the reaction routes.

\section{Experimental}

\subsection{Material}

The pyroligneous acid was produced from slow pyrolysis of dried Japanese cedar woodchips for char production using a horizontal screw-conveyor reactor. The chips have an average size of $10 \times 10 \times 2 \mathrm{~mm}, 50.9$ wt.\% carbon and 3 
wt. \% moisture content. The pyrolysis was carried out with a feeding rate, an average residence time, a heating rate, a peak temperature, and a gas pressure inside the reactor of $270 \mathrm{~g} \mathrm{~h}^{-1}, 47 \mathrm{~s}, 5.0-5.5{ }^{\circ} \mathrm{C} \mathrm{s}^{-1}, 500{ }^{\circ} \mathrm{C}$, and 1.0 atm, respectively [2]. The slow pyrolysis produces char, heavy tar, light tar which consist of two separate phases: organic liquid (water-insoluble fraction) and pyroligneous acid (water-soluble fraction), and gaseous products. Carbon concentration of feed for the pyrolysis (woodchips) and the products (char, heavy tar, organic liquid, pyroligneous acid) was analyzed by elemental analysis (Costech, ECS 4010 CHNS-O) and the weights of used feed and the products were measured and then, each of them was calculated in $\mathrm{C}$ mol. During the pyrolysis, gas and non-condensable volatile (gaseous products) were collected in gas pack and then analyzed by gas chromatography with TCD and FID detectors. Total gas produced was also calculated in $\mathrm{C}$ mol. All the products after the pyrolysis were divided by $\mathrm{C}$ mol used feed to determine the yield in $\mathrm{C}$ mol\%.

Furthermore, the chemical compositions of pyroligneous acid (feed for the catalytic reaction) were analyzed using a GC-17A (Shimadzu, CP-Pora PLOT Q capillary column) for identification of volatile chemical compounds such as acetaldehyde, methanol, acetone, and 2-butanone using ethanol as an internal standard. Then, higher vapor pressure chemicals such as hydroxyacetone, acetic acid, phenol were analyzed by a GC-2014 (Shimadzu, DB-WX capillary column), and a GC/MS-QP5050 (Shimadzu, CP-Pora PLOT Q_DB-WX capillary columns) with n-butanol as an internal standard. Because heavy components undetectable by gas chromatography were contained in the pyroligneous acid, the amount of carbon measured by elemental analysis was considered to be the total amount of carbon in the pyroligneous acid. The yield of pyroligneous acid was shown as $\mathrm{C} \mathrm{mol \%} \mathrm{by} \mathrm{divided} \mathrm{C}$ mol pyroligneous acid based on GC analysis with its $\mathrm{C}$ mol based on elemental analysis. Moreover, the GC/MS analysis was used for the quantitative identification of chemical compounds in the pyroligneous acid. Then, the amount of metal impurities in the pyroligneous acid was determined by X-ray fluorescence (XRF, Rigaku Corporation, Supermini-GR16008).

\subsection{Catalyst preparation and characterization}

All reagents were purchased from Wako Pure Chemical Industries, Ltd (Japan). The zirconia-supported iron-oxide $\left(\mathrm{ZrO}_{2}(\mathrm{Y})-\mathrm{FeO}_{\mathrm{X}}: \mathrm{Y}=\right.$ wt. $\left.\% \mathrm{ZrO}_{2}\right)$ catalysts were prepared using a co-precipitation method in an aqueous solution of $\mathrm{Fe}\left(\mathrm{NO}_{3}\right)_{3} \cdot 9 \mathrm{H}_{2} \mathrm{O}$ and $\mathrm{ZrO}\left(\mathrm{NO}_{3}\right)_{2} \cdot 2 \mathrm{H}_{2} \mathrm{O}$ using aqueous ammonia. The obtained catalysts were calcined at $773 \mathrm{~K}$ for $2 \mathrm{~h}$ in an air atmosphere [9]. Catalysts with $\mathrm{ZrO}_{2}$ content of 8.9, 50, and 70 wt.\% were prepared, and their crystallinity characterized by X-ray diffraction (XRD, JEOL, JDX-8020).

\subsection{Cation-exchange treatment for the pyroligneous acid}


$\mathrm{XRF}$ analysis revealed that the pyroligneous acid contained potassium $(\mathrm{K})$ and magnesium $(\mathrm{Mg})$ as metal impurities. A cation-exchange resin [MP Biomedicals, LLC: Amberlite®IR-120 plus (H)] was used to remove alkali and alkaline earth metals such as $\mathrm{K}$ and $\mathrm{Mg}$ from the pyroligneous acid. The treatment was carried out in standard glass bottle $(25 \mathrm{ml}$ ) by placing $5 \mathrm{ml}$ of pyroligneous acid into $2 \mathrm{~g}$ of the resin for $24 \mathrm{~h}$ at $275 \mathrm{~K}$ with occasional shaking.

\subsection{Catalytic reaction}

Catalytic reactions were carried out in a fixed bed flow reactor for $2 \mathrm{~h}$ at $623-723 \mathrm{~K}$ under atmospheric pressure. Figure 1 shows a schematic of the experimental apparatus. $\mathrm{ZrO}_{2}-\mathrm{FeO}_{\mathrm{X}}$ catalysts were pelletized without any binders, then crushed and sieved to provide pieces $300-850 \mu \mathrm{m}$ in diameter. The pyroligneous acids prior to and after cationexchange treatment were used as feedstocks. Nitrogen gas $\left(10 \mathrm{~cm}^{3} \mathrm{~min}^{-1}\right)$ was introduced as the carrier gas. The pyroligneous acids and $\mathrm{H}_{2} \mathrm{O}$ were mixed in a 1:1 weight ratio and fed into the reactor at $2 \mathrm{ml} \mathrm{h}^{-1}$ using a syringe pump. The time-factors, $W / F$, were 1-4 h. The liquid and gaseous products were collected in an ice/water trap and gas pack, respectively. The liquid product and catalyst crystallinity after each reaction were analyzed using the same gas chromatographs, elemental analyzer, and XRD as mentioned above. Gaseous products were analyzed by gas chromatography [GS-20B (Shimadzu, FID detector) and GC-8A (Shimadzu, TCD detector)].

\section{Results and Discussion}

\subsection{Chemical composition of the pyroligneous acid}

During pyrolysis of the woodchips biomass, organic chemical bonds such as $\mathrm{C}-\mathrm{C}$ and $\mathrm{C}-\mathrm{O}$ bonds were decomposed by dehydration, hydrolysis, oxidation, decarboxylation, and depolymerization to produce gaseous products, water vapor, tar, and volatiles. The water vapor, tar, and volatiles generated from the biomass were condensed and collected by filter and cold traps of different temperatures (393, 278, and $233 \mathrm{~K}$, respectively), and three types of tar (heavy tar, an organic liquid fraction and pyroligneous acid) were obtained. Incondensable volatiles and gaseous products were recovered as gas products. The remaining residue of the pyrolysis process was recovered as char. Yields of the pyroligneous acid, the organic liquid and heavy tar on the basis of carbon concentration in the woodchips were 14.0, 3.3, and $39.8 \mathrm{C} \mathrm{mol} \%$, respectively, and the yields of all of pyrolysis products including gas and char are listed in Table 1.

Since the chemicals contained in the pyroligneous acid dissolved in water, it was considered that they consisted of polar compounds of low molecular weight, and thus the pyroligneous acid was mainly derived from the pyrolysis of 
cellulose and hemicellulose. On the other hand, the portion of the organic liquid that was insoluble in water was considered to be derived from lignin [11]. In this study, the pyroligneous acid, which was an organic-containing water solution, was selected as the feedstock for the catalytic reaction, and the amount of carbon in the water measured by elemental analysis was approximately $20.7 \mathrm{wt} \%$. Based on data from GC and GCMS analyses, the chemical compounds in the pyroligneous acid were grouped into hydroxyacetone, aliphatic ketones (acetone, 2-butanone, and 3pentanone), carboxylic acids (acetic and propionic acids), cyclic ethers and ketones, aldehydes, methanol, phenols, light components (detectable by GC), and heavy components (undetectable by GC). Yields of hydroxyacetone, aliphatic ketones, and carboxylic acids on the basis of carbon concentration in the pyroligneous acid were 7.0, 4.3, and 8.6 C mol\%, respectively, and detailed yields of all of chemical composition are shown in Table 2.

\subsection{Effect of reaction temperature on product yields and catalyst stability}

To understand the effect of temperature during the catalytic reaction of the pyroligneous acid, reactions were carried out at 623,673 , and $723 \mathrm{~K}$. Product yields after reaction using a $\mathrm{ZrO}_{2}(8.9)-\mathrm{FeO}_{\mathrm{X}}$ catalyst are shown in Fig. 2. Product yields without catalyst are also shown in this figure for comparison. Because many chemicals undetectable by the gas chromatographs were contained in the pyroligneous acid, the amount of carbon measured by the elemental analyzer was assumed to be the total amount of carbon in the pyroligneous acid. The product yield without catalyst was almost the same as the composition of the feedstock. In contrast, in the reaction over $\mathrm{ZrO}_{2}(8.9)-\mathrm{FeO}_{\mathrm{X}}$ at $623 \mathrm{~K}$, the yield of hydroxyacetone decreased, whereas the yields of carboxylic acids and aliphatic ketones increased.

In order to investigate the reaction mechanism, we carried out catalytic reactions using aqueous solutions of hydroxyacetone, carboxylic acids, and an aliphatic ketone as model compounds representing the pyroligneous acid. The yields of the main products from these reactions are listed in Table 3. Acetone was essentially inert during reaction over

the $\mathrm{ZrO}_{2}-\mathrm{FeO}_{\mathrm{X}}$ catalyst. Acetic and propionic acids were selectively converted into acetone and 3-pentanone, respectively. Moreover, hydroxyacetone was easily converted into acetic and propionic acids, which then further reacted to form acetone, 2-butanone, and 3-pentanone via a ketonization process. The anticipated reaction routes for production of aliphatic ketones from hydroxyacetone and carboxylic acids over $\mathrm{ZrO}_{2}-\mathrm{FeO}_{\mathrm{X}}$ can be seen in Fig. 3. Based on the product yields obtained from these model compounds and the reaction routes shown, the changes in the product yields shown in Fig. 2 were ascribed to a ketonization reaction of carboxylic acids in the pyroligneous acid that took place over the catalyst.

As shown in Fig. 2, the yield of gaseous products, mainly $\mathrm{CO}_{2}$, increased considerably and the yield of heavy components decreased when the reaction temperature increased from 623 to $723 \mathrm{~K}$. In the ketonization reaction, two molecules of carboxylic acids are converted into one molecule of ketone and $\mathrm{CO}_{2}$. However, the amount of $\mathrm{CO}_{2}$ 
generated during the reaction was larger than that calculated for the ketonization. Accordingly, the generation of $\mathrm{CO}_{2}$ was ascribed to oxidation of the heavy components in the pyroligneous acid. Moreover, the product yield of aliphatic ketones gradually decreased with increasing reaction temperature, indicating that the aliphatic ketones produced from the carboxylic acids were oxidized at 673 and $723 \mathrm{~K}$ because of the high reaction temperatures.

XRD patterns of the $\mathrm{ZrO}_{2}(8.9)-\mathrm{FeO}_{\mathrm{X}}$ catalyst prior to and after reactions at 623, 673, and $723 \mathrm{~K}$ are shown in Fig. 4. The patterns of the catalyst prior to and after the reaction at $623 \mathrm{~K}$ showed peaks corresponding to hematite (alpha$\mathrm{Fe}_{2} \mathrm{O}_{3}$ ). The patterns of the catalysts after reaction at 673 and $723 \mathrm{~K}$, in contrast, showed peaks corresponding to magnetite $\left(\mathrm{Fe}_{3} \mathrm{O}_{4}\right)$. It was considered that the heavy and lighter components, as well as other chemicals, were oxidized using the lattice oxygen of iron oxide, where oxygen defects were formed within the hematite structure. The consumed lattice oxygen was regenerated by oxygen-active species that were produced on $\mathrm{ZrO}_{2}$ by decomposition of $\mathrm{H}_{2} \mathrm{O}$ molecules $[10,12]$. At the high reaction temperatures of 673 and $723 \mathrm{~K}$, excessive consumption of lattice oxygen occurred during the reaction, leading to the change in crystallinity of the catalyst from hematite to magnetite. Therefore, it was decided that $623 \mathrm{~K}$ was the appropriate reaction temperature.

\subsection{Effect of $\mathrm{ZrO}_{2}$ content in the catalyst on catalytic activity}

In the pyroligneous acid, the light and heavy components derived from pyrolytic decomposition of cellulose were present at approximately 15 and $45 \mathrm{C} \mathrm{mol \% ,} \mathrm{respectively.} \mathrm{It} \mathrm{was} \mathrm{considered} \mathrm{that} \mathrm{decomposition} \mathrm{of} \mathrm{the} \mathrm{light} \mathrm{and} \mathrm{heavy}$ components in the pyroligneous acid over the catalyst caused new production of hydroxyacetone and carboxylic acids, leading to an increase in the ketone yield because hydroxyacetone and carboxylic acids were source chemicals for ketone production, as shown in Fig. 3. On the other hand, the $\mathrm{ZrO}_{2}-\mathrm{FeO}_{\mathrm{X}}$ catalysts possessed oxidative decomposition activity towards the heavy components using the lattice oxygen in $\mathrm{FeO}_{\mathrm{X}}$, which was accelerated by adding $\mathrm{ZrO}_{2}$ on the $\mathrm{FeO}_{\mathrm{X}}[9]$. Moreover, the oxygen defects in the $\mathrm{FeO}_{\mathrm{X}}$ formed during the decomposition of the heavy components were regenerated by oxygen-active species produced from $\mathrm{H}_{2} \mathrm{O}$ molecules over $\mathrm{ZrO}_{2}$. Accordingly, the effects of $\mathrm{ZrO}_{2}$ content on aliphatic ketone yield were examined and are presented in Fig. 5. As the $\mathrm{ZrO}_{2}$ content increased, the yield of the heavy components decreased, and the yield of residue deposited on the catalyst increased. Since $\mathrm{ZrO}_{2}$ possesses the properties of a solid acid, the increase in the amount of coke-like residue on the catalyst was ascribed to the increase in the $\mathrm{ZrO}_{2}$ content. On the basis of the catalytic stability shown in Fig. 4 and the amount of coke-like residue on the catalyst shown in Fig. 5, the $\mathrm{ZrO}_{2}(8.9)-\mathrm{FeO}_{\mathrm{X}}$ catalyst was determined to be an appropriate catalyst.

In our previous research, it was revealed that an increase in the amount of $\mathrm{ZrO}_{2}$ in $\mathrm{ZrO}_{2}-\mathrm{FeOx}$ catalysts enhances the catalytic activity to produce ketones from biomass-derived tar [8]. As shown in Fig. 5, the total yield of aliphatic ketones and carboxylic acids slightly increased with increasing amounts of $\mathrm{ZrO}_{2}$ up to 50 wt.\%. The yield of aliphatic 
ketones was almost unchanged, however, regardless of $\mathrm{ZrO}_{2}$ content. During pyrolysis of woodchips biomass, alkali and alkaline earth metals, essential metals contained in the biomass were released from the woodchips and dissolved in the pyroligneous acid. XRF analysis of the pyroligneous acid revealed that potassium $(\mathrm{K})$ and magnesium $(\mathrm{Mg})$ were present at concentrations of 580 and 430 ppm, respectively. Accordingly, it was considered that these metal impurities were deposited on the catalyst to de-activate the ketonization activity.

\subsection{Removal of metal impurities and effect of W/F on ketone yields}

As mentioned above, because it was considered that the metal impurities such as $\mathrm{K}$ and $\mathrm{Mg}$ were catalytic poisons and decreased catalytic activity, a cation-exchange resin was used to remove these metals from the pyroligneous acid. After ion-exchange treatment using the cation-exchange resin, $\mathrm{K}$ and $\mathrm{Mg}$ were recognized as trace elements in the pyroligneous acid by XRF analysis. The product yields after catalytic reactions over the $\mathrm{ZrO}_{2}(50)-\mathrm{FeO}_{\mathrm{X}}$ catalyst are shown in Fig. 6. Pyroligneous acids prior to and after cation-exchange treatment were used as feedstocks. The chemical compositions of the feeds are also shown in this figure for comparison.

Since the compositions of the pyroligneous acids prior to and after cation-exchange treatment were almost unchanged, the metal impurities such as $\mathrm{K}$ and $\mathrm{Mg}$ were selectively removed from the pyroligneous acid. Moreover, when using the pyroligneous acid after removing the metal impurities, the yield of aliphatic ketones was increased as compared to the reaction with the pyroligneous acid prior to the cation-exchange treatment. Accordingly, it was considered that these metal impurities reduced the catalytic activity for production of aliphatic ketones and hence the cation-exchange treatment to remove $\mathrm{K}$ and $\mathrm{Mg}$ from the pyroligneous acid was effective in avoiding catalyst deactivation by the deposition of alkali and alkaline earth metals.

Next, the effect of catalyst weight ( $W / F$ value) on product yields was examined to determine if the yield of aliphatic ketones could be increased. Product yields from reactions over $\mathrm{ZrO}_{2}(8.9)-\mathrm{FeO}_{\mathrm{X}}$ with different $W / F$ values using the pyroligneous acid without metal impurities (the pyroligneous acid after cation-exchange treatment) can be seen in Fig. 7. Although more coke-like residue was deposited on the catalyst as the $W / F$ value increased, the yield of light and heavy components decreased and the yield of aliphatic ketones increased. As discussed above, hydroxyacetone is converted into carboxylic acids and then two molecules of carboxylic acids produce one molecule of ketone. Aliphatic ketone yields were higher than expected, though, on the basis of the amount of hydroxyacetone and carboxylic acids in the pyroligneous acid, as shown in Fig. 7. These results indicated that the decomposition of light and heavy components occurred using the lattice oxygen in $\mathrm{FeO}_{\mathrm{X}}$ to produce carboxylic acids, leading to the production of additional amounts of the aliphatic ketones from the carboxylic acids that were newly formed over the $\mathrm{ZrO}_{2}-\mathrm{FeO}_{\mathrm{X}}$ catalyst. Accordingly, the $\mathrm{ZrO}_{2}-\mathrm{FeO}_{\mathrm{X}}$ catalyst is an appropriate catalyst for producing aliphatic ketones from 
pyroligneous acid derived from woody biomass. The maximum yield of aliphatic ketones reached approximately $30 \mathrm{C}$ mol\% at a $W / F$ of $4 \mathrm{~h}$, and the fraction of aliphatic ketones in the obtained liquid product reached $55 \mathrm{C}$ mol\%, with the main products consisting of 2-butanone $(22 \mathrm{C} \mathrm{mol} \%)$ and acetone $(33 \mathrm{C} \mathrm{mol} \%)$.

\section{Conclusions}

Catalytic reactions of organic-containing water solutions (pyroligneous acid) derived from slow pyrolysis of Japanese cedar woodchips were carried out in a fixed bed reactor using $\mathrm{ZrO}_{2}-\mathrm{FeO}_{\mathrm{X}}$ catalysts. In this study, $\mathrm{ZrO}_{2}-\mathrm{FeO}$ was an appropriate catalyst with high activity for the selective production of ketones (acetone and 2-butanone) from the pyroligneous acid. The presence of metal impurities such as $\mathrm{K}$ and $\mathrm{Mg}$ in the pyroligneous acid, however, inhibited catalytic activity. Removal of the metal cations from the pyroligneous acid using a cation-exchange resin was effective, though, for maintaining catalytic activity for ketone production. The maximum ketone yield reached approximately 30 $\mathrm{C}$ mol\% at a reaction temperature of $623 \mathrm{~K}$ and a $W / F$ value of $4 \mathrm{~h}$.

\section{Acknowledgment}

This work was supported by the Global COE Program (Project No. B01: Catalysis as the Basis for Innovation in Materials Science) from the Ministry of Education, Culture, Sports, Science and Technology, Japan).

\section{References}

[1] Van de Steene L, Tagutchou JP, Mermoud F, Martin E, Salvador S. A new experimental continuous fixed bed reactor to characterize wood char gasification. Fuel 2010; 89:3320.

[2] Kajita M, Kimura T, Norinaga K, Li CZ, Hayashi Ji. Catalytic and noncatalytic mechanisms in steam gasification of char from the pyrolysis of biomass. Energy Fuels 2010;24:108.

[3] Bridgwater AV, Cottam M-L. Opportunities for biomass pyrolysis liquids production and upgrading. Energy Fuels 1992;6:113.

[4] Branca C, Giudicianni P, Blasi CD. GC/MS characterization of liquids generated from low-temperature pyrolysis of wood. Ind. Eng. Chem. Res. 2003; 42:3190.

[5] Bridgwater AV, Carson P, Coulson M. A comparison of fast and slow pyrolysis liquids from mallee. Int. J. Global Energy Issues 2007;27:204.

[6] Honnery D, Ghojel J, Stamatov V. Performance of a DI diesel engine fuelled by blends of diesel and kilnproduced pyroligneous tar. Biomass Bioenergy 2008;32:358. 
[7] Masuda T, Kondo Y, Miwa M, Shimotori T, Mukai SR, Hashimoto K, Takano M, Kawasaki S, Yoshida S. Recovery of useful hydrocarbons from oil palm waste using $\mathrm{ZrO}_{2}$ supporting FeOOH catalyst. Chem. Eng. Sci. 2001;56:897.

[8] Fumoto E, Mizutani Y, Tago T, Masuda T. Production of ketones from sewage sludge over zirconia-supporting iron oxide catalysts in a steam atmosphere. Appl. Catal., B 2006;68:154.

[9] Funai S, Satoh Y, Satoh Y, Tajima K, Tago T, Masuda T. Development of a new conversion process consisting of hydrothermal treatment and catalytic reaction using $\mathrm{ZrO}_{2}-\mathrm{FeO}_{\mathrm{X}}$ catalyst to convert fermentation residue into useful chemicals. Top. Catal. 2010;53:654.

[10] Fumoto E, Tago T, Tsuji T, Masuda T. Recovery of useful hydrocarbons from petroleum residual oil by catalytic cracking with steam over zirconia-supporting iron oxide catalyst. Energy Fuels 2004;18:1170.

[11] Sipilä K, Kuoppala E, Fagernäs L, Oasmaa A. Characterization of biomass-based flash pyrolysis oils. Biomass Bioenergy 1998;14-2:103.

[12] Masuda T, Miwa Y, Hashimoto K, Ikeda Y. Recovery of oil from waste poly(ethylene terephthalate) without producing any sublimate materials. Polym. Degrad. Stab. 1998;61:217. 
Tables:

Table 1. Yields of pyrolysis products from woodchips.

\begin{tabular}{lc}
\hline & Yield $^{\mathrm{a}}(\mathrm{C} \mathrm{mol \%})$ \\
\hline \hline Pyroligneous acid & 14.0 \\
Organic liquid fraction & 3.3 \\
Heavy tar & 39.8 \\
Gaseous & 3.0 \\
Char & 39.9 \\
\hline
\end{tabular}

(a) Based on the woodchips carbon. 
Table 2. Chemical composition of the pyroligneous acid.

\begin{tabular}{lc}
\hline & Composition $^{\mathrm{b}}(\mathrm{C} \mathrm{mol} \%)$ \\
\hline Hydroxyacetone & 7.0 \\
Aliphatic ketones & 4.3 \\
Carboxylic acids & 8.6 \\
Cyclic ethers and ketones & 5.4 \\
Aldehydes & 1.6 \\
Methanol & 5.0 \\
Phenols & 7.0 \\
Light components & 16.0 \\
Heavy components & 45.1 \\
\hline \multicolumn{2}{c}{ (b) Based on the pyroligneous acid carbon. }
\end{tabular}


Table 3. Yields of main reaction model compounds.

\begin{tabular}{|c|c|c|}
\hline Reactant & Main Product & Yield (C mol\%) \\
\hline Acetone $^{c}$ & Acetone & 92.0 \\
\hline Acetic acid ${ }^{\mathrm{c}}$ & Acetone & 62.6 \\
\hline Propionic acid ${ }^{\mathrm{c}}$ & 3-Pentanone & 45.8 \\
\hline \multirow{5}{*}{ Hydroxyacetone $^{\mathrm{d}}$} & Acetone & 17.1 \\
\hline & 2-Butanone & 14.8 \\
\hline & 3-Pentanone & 8.6 \\
\hline & Acetic acid & 0.1 \\
\hline & Propionic acid & 0.7 \\
\hline
\end{tabular}
(c) Refer to Ref. [9].
(d) Reaction conditions: $\mathrm{ZrO}_{2}(8.9)-\mathrm{FeO}_{\mathrm{X}}$ catalyst, $W / F=1 \mathrm{~h}, \mathrm{~T}=623 \mathrm{~K}, \mathrm{~F}=10 \mathrm{wt} \%$ hydroxyacetone solution. 
Figures:

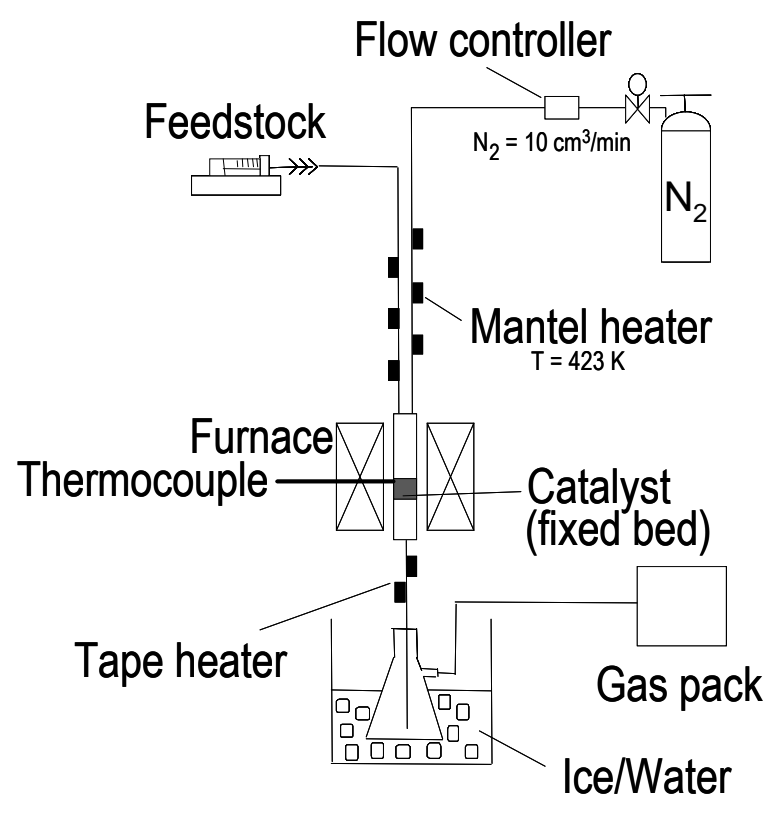

Fig. 1. Schematic of experimental apparatus. 


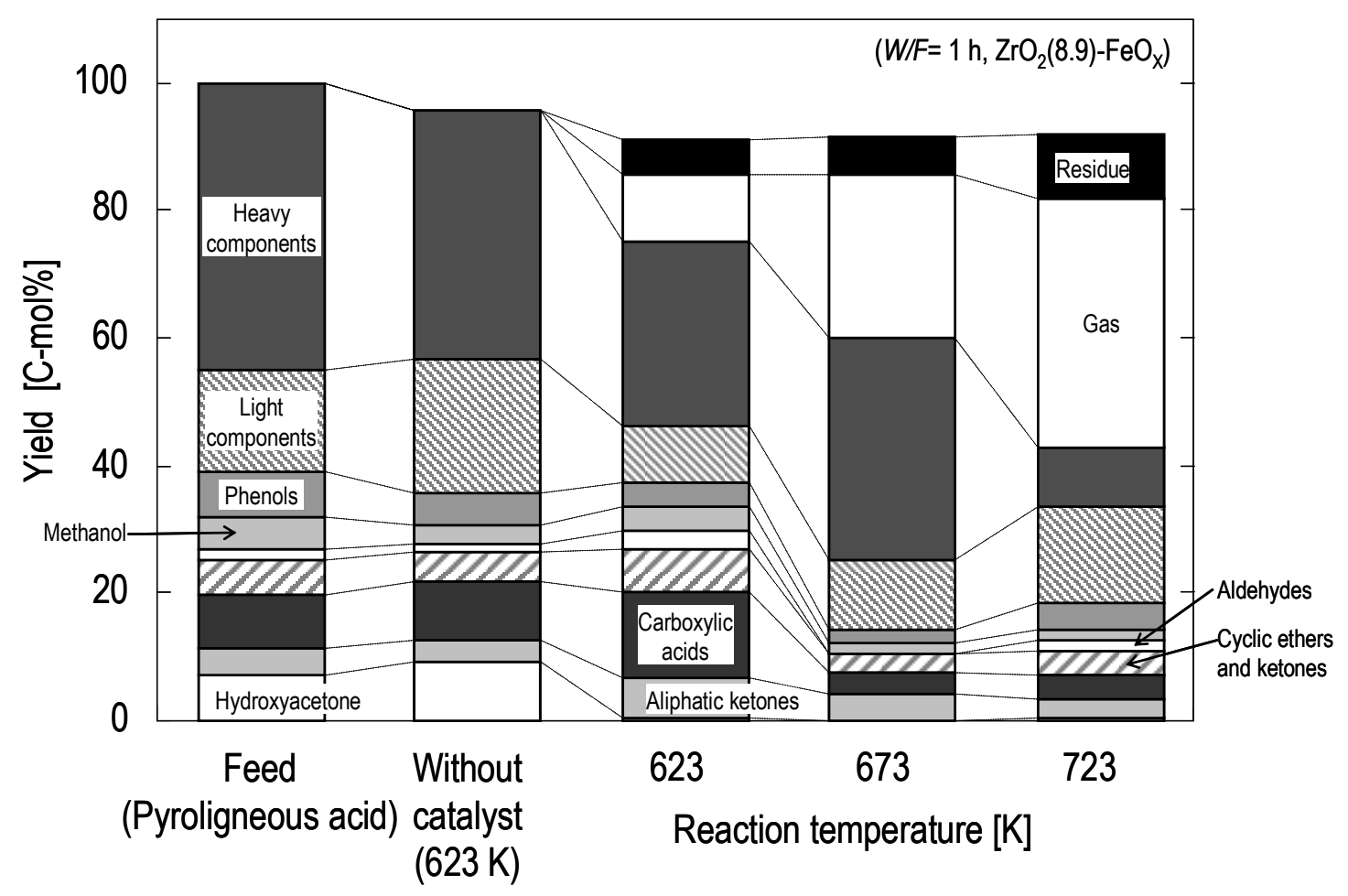

Fig. 2. Effect of reaction temperature on product yields. 

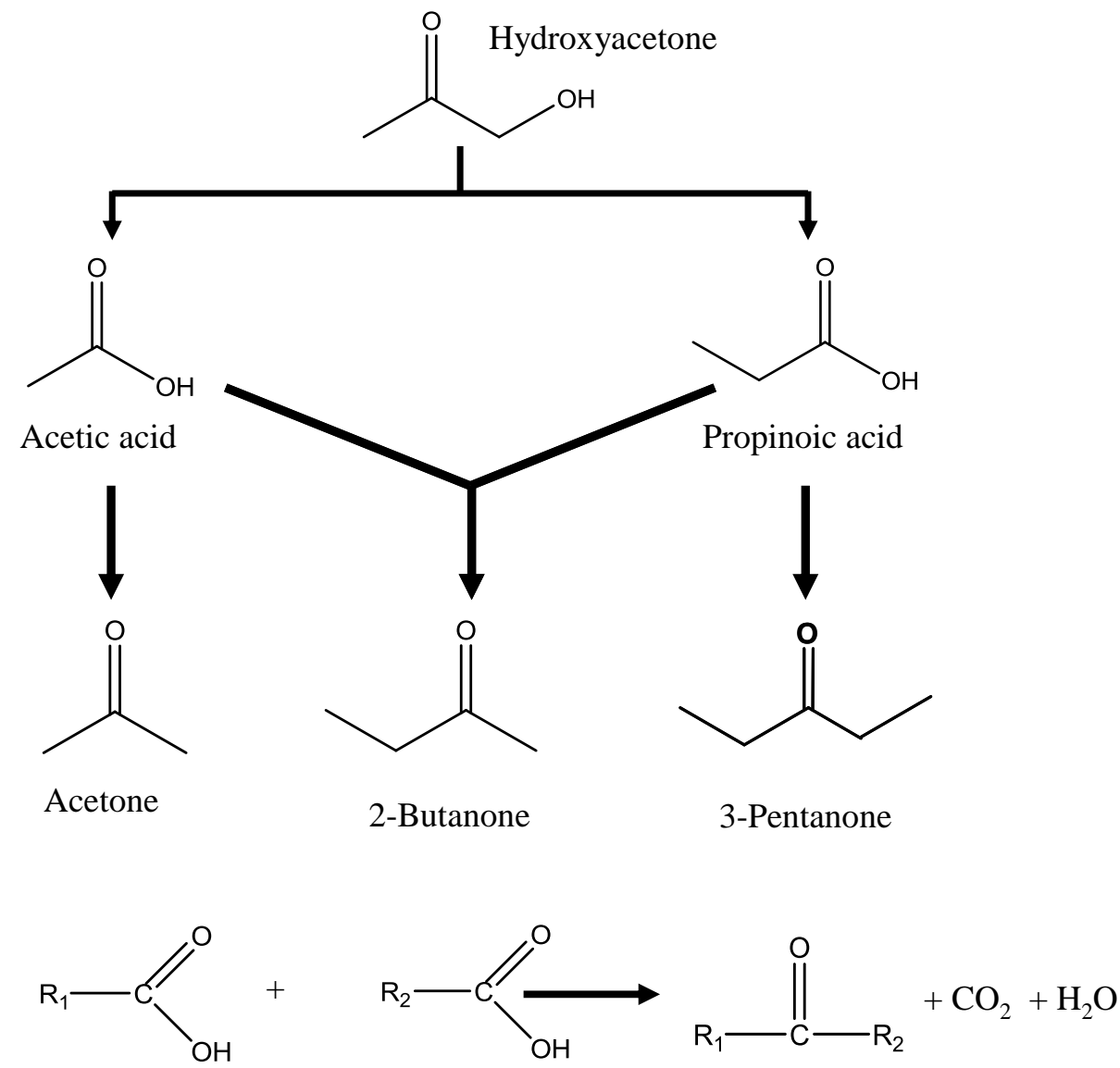

\section{Carboxylic acid \\ Carboxylic acid \\ Ketone}

Fig. 3. Anticipated reaction routes for production of ketones from hydroxyacetone and carboxylic acids over $\mathrm{ZrO}_{2}-\mathrm{FeO}_{\mathrm{X}}$ catalyst. 


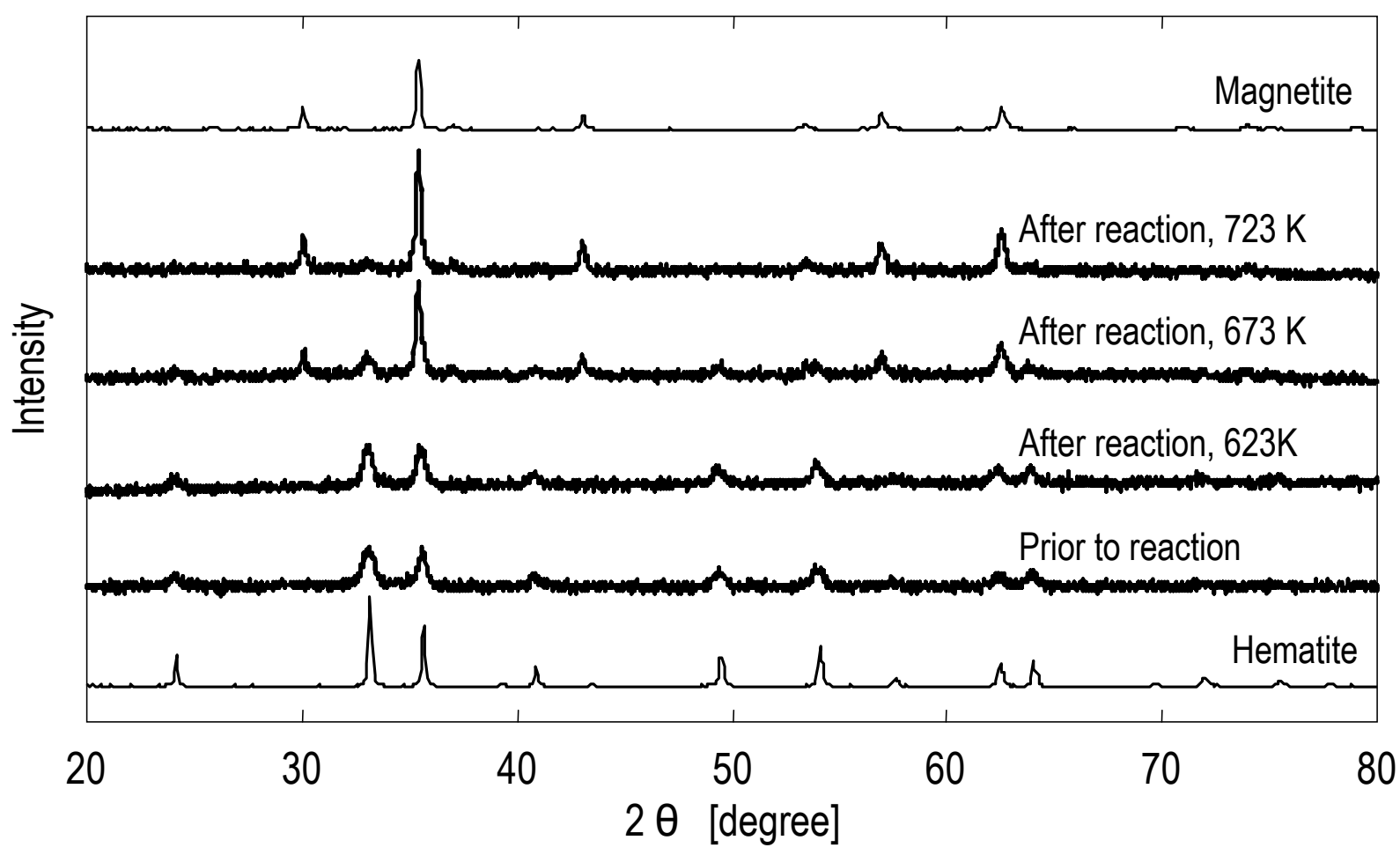

Fig. 4. X-ray diffraction patterns of $\mathrm{ZrO}_{2}-\mathrm{FeO}_{\mathrm{X}}$ catalyst prior to and after reactions at different temperatures. 


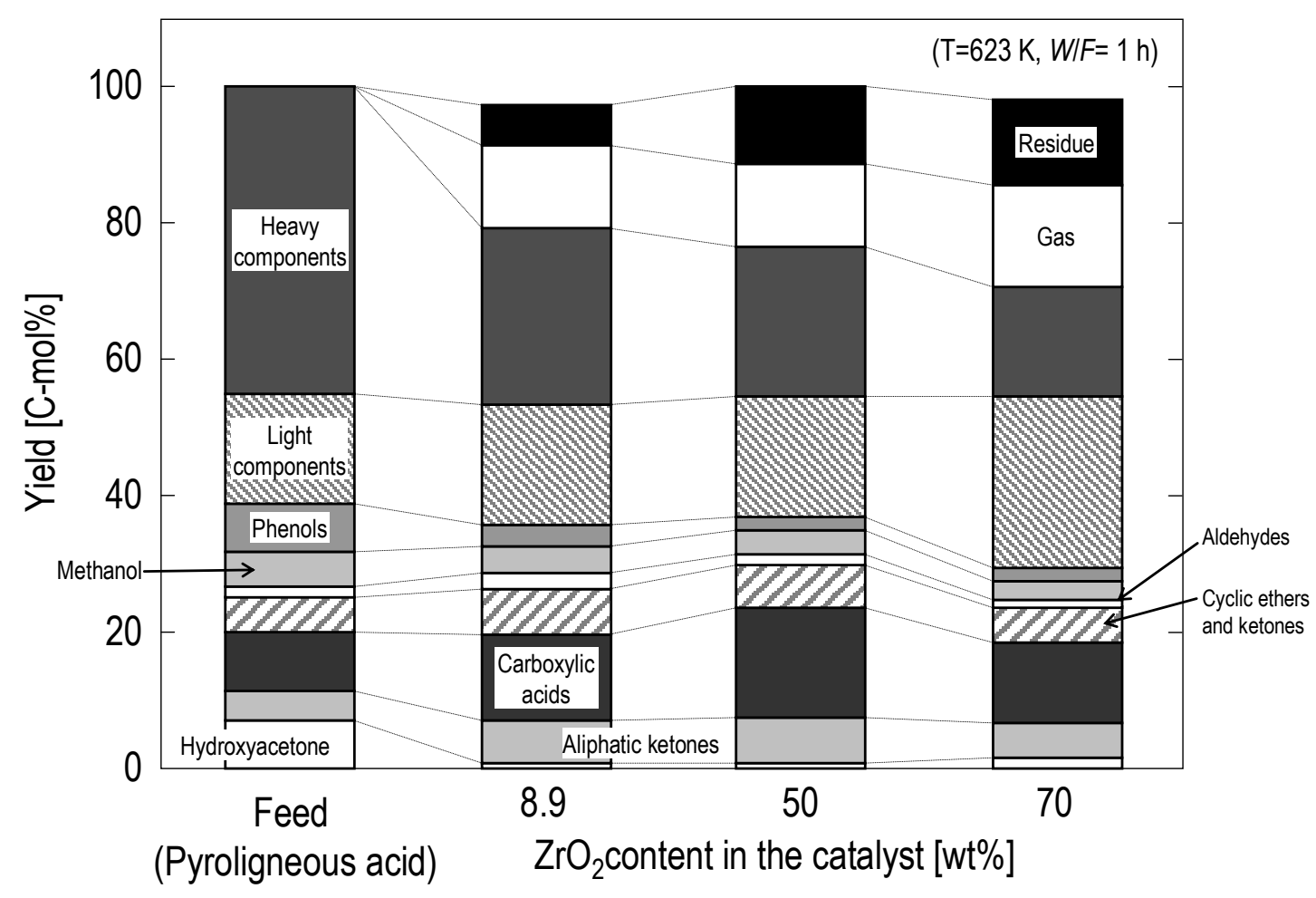

Fig. 5. Effect of $\mathrm{ZrO}_{2}$ content in the catalyst on product yields. 


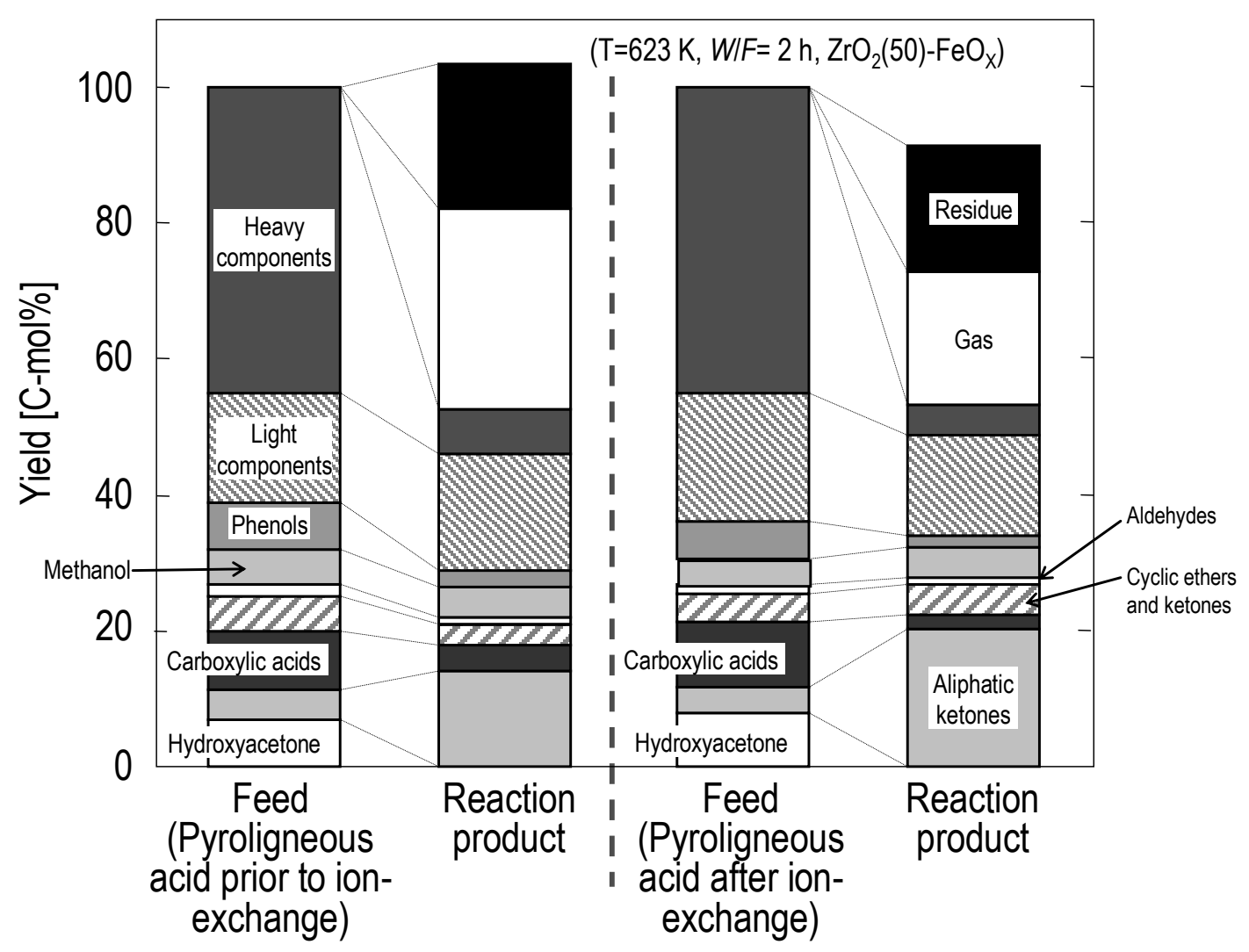

Fig. 6. Effect of cation-exchange resin treatment on pyroligneous acid composition and product yields. 


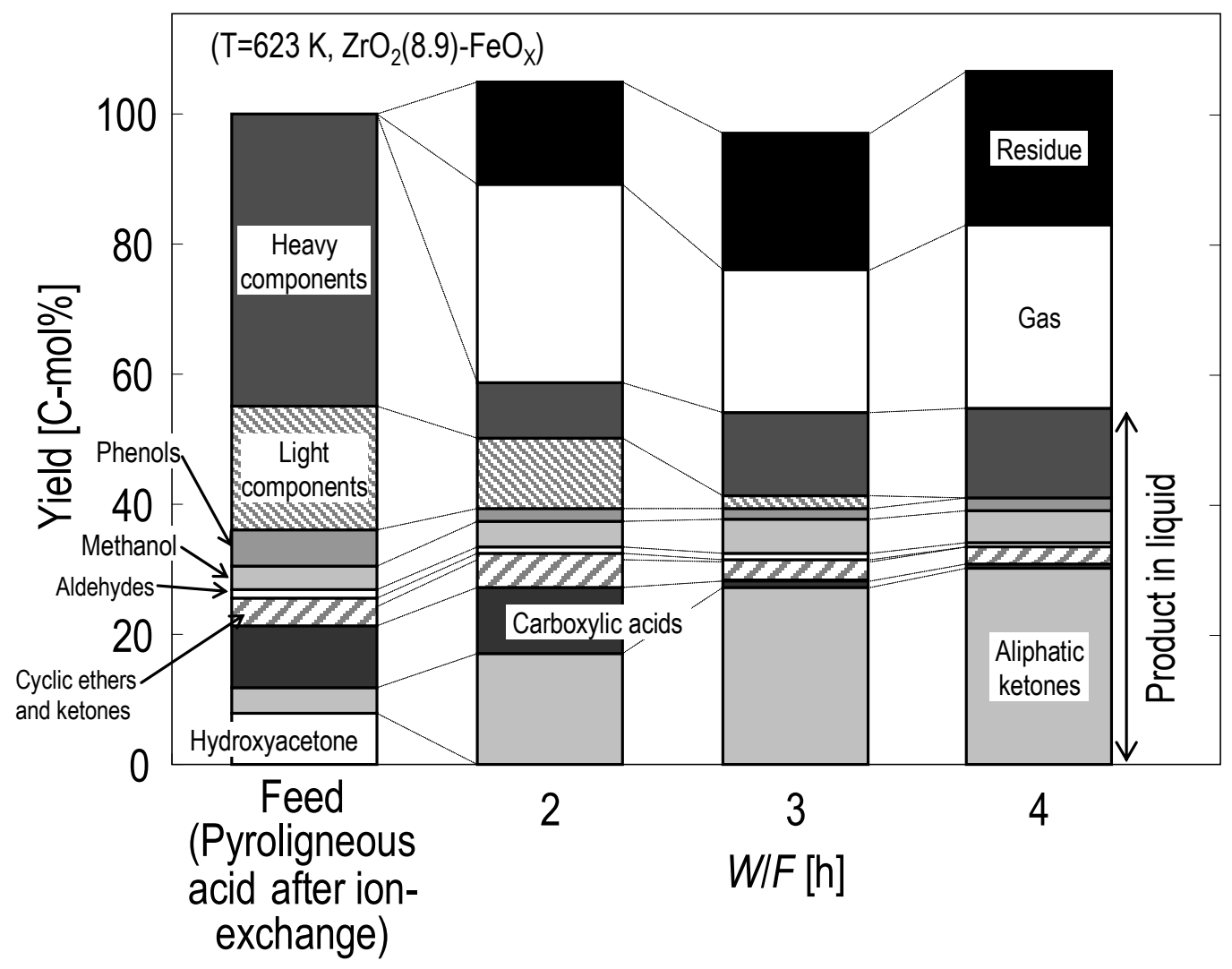

Fig. 7. Effect of $W / F$ values on product yields. 